HOFFMAM, Fernando, MORAIS, Jose Luis Bolzan de. A prática dos Juizados Especiais Federais entre pragmatismo e respostas corretas. Revista Eletrônica Direito e Política, Programa de Pós-Graduação Stricto Sensu em Ciência Jurídica da UNIVALI, Itajaí, v.13, n.2, 20 quadrimestre de 2018. Disponível em: www.univali.br/direitoepolitica - ISSN 1980-7791

\title{
A PRÁTICA DOS JUIZADOS ESPECIAIS FEDERAIS ENTRE PRAGMATISMO E RESPOSTAS CORRETAS
}

\author{
THE PRACTICE OF SPECIAL FEDERAL JUDGES AMONG PRAGMATISM AND \\ CORRECT ANSWERS
}

Fernando Hoffmam ${ }^{1}$

Jose Luis Bolzan de Morais ${ }^{2}$

SUMÁRIO: Introdução; 1 Os Juizados Especiais Federais e o modelo de "Conciliação Pragmática"; 2 Os Juizados Especiais Federais como locus de respostas consensualmente jurisconstruídas; Considerações finais; Referências das fontes citadas.

\section{RESUMO}

O presente trabalho propõe-se a compreender a lógica de funcionamento dos Juizados Especiais Federais (JEFs) entre eficiencia e efetividade, tendo como cenário para tal compreensão a análise econômica do direito e a crítica dworkiniana à mesma. A partir desse contexto, propõe-se ao invés de uma "conciliação pragmática" no ambiente dos JEFs, a construção de um ambiente afeito à jurisconstrução de respostas jurídico-volitivas-consensuais, unindo as teorias de Ronald Dworkin, Luis Alberto Warat e Jose Luis Bolzan de Morais, buscando a concretização de um espaço-tempo efetivamente democrático.

Palavras-chave: Conciliação Pargmática; Consenso; Juizados Especiais Federais; Jurisconstrução.

\section{ABSTRACT}

This work intends to understand the logic of Small Federal Claims Courts between efficiency and effectiveness, having as a scenario for such an understanding the economic analysis of the law and Dworkin's criticism of it. From this context,

\footnotetext{
1 Mestre e Doutorando em Direito Público pela Universidade do Vale do Rio dos Sinos (UNISINOS); Bolsista PROEX/CAPES; Membro do Grupo de Pesquisa Estado e Constituição e da Rede Interinstitucional de Pesquisa Estado e Constituição, vinculado à UNISINOS e ao CNPQ; Professor Titular do Curso de Direito da Universidade Regional Integrada do Alto Uruguai e das Missões (URI/ Câmpus Santiago); Membro do Grupo de Pesquisa Direito, Justiça e Cidadania, vinculado à URI e ao CNPQ; Especialista em Direito: Temas Emergentes em Novas Tecnologias da Informação e Bacharel em Direito pelo Centro Universitário Franciscano (UNIFRA). E-mail: ferdhoffa@yahoo.com.br.

2 Pós-Doutor em Direito Constitucional pela Universidade de Coimbra; Doutor em Direito do Estado pela Universidade Federal de Santa Catarina (UFSC) e pela Université de Montpellier I; Mestre em Ciências Jurídicas pela Pontifícia Universidade Católica do Rio de Janeiro (PUC-RJ); Professor do Programa de Pós-Graduação - Mestrado e Doutorado - da Universidade do Vale do Rio dos Sinos (UNISINOS); Procurador do Estado do Rio Grande do Sul. E-mail: bolzan@hotmail.com
} 
HOFFMAM, Fernando, MORAIS, Jose Luis Bolzan de. A prática dos Juizados Especiais Federais entre pragmatismo e respostas corretas. Revista Eletrônica Direito e Política, Programa de Pós-Graduação Stricto Sensu em Ciência Jurídica da UNIVALI, Itajaí, v.13, n.2, 20 quadrimestre de 2018. Disponível em: www.univali.br/direitoepolitica - ISSN 1980-7791

instead of a "pragmatic conciliation" in the Small Federal Claims Courts environment, the construction of an environment conducive to the jurisconstruction of juridical, volitional and consensual answers, uniting the theories of Ronald Dworkin and Jose Luis Bolzan de Morais, aiming at the concretization of an effectively democratic space-time.

Keywords: Pragmatic Conciliation; Consensus; Small Federal Claims Courts; Jurisconstruction.

\section{INTRODUÇÃO}

Os Juizados Especiais Federais (JEFs) se encontram num dilema cruzado, transitando entre uma postura eficienticista abarcada pela lógica de produtividade decisória e eliminação de processos, e, coadunar-se com fim ao qual foi primeiramente pensado, ou seja, como um espaço democrático de construção de respostas. Quando se lança à eficiência, caminha lado a lado com a análise econômica do direito e, assim, constitui-se enquanto um espaço-tempo de operacionalidade da "conciliação pragmática" (Parte 1).

No entanto, devem os JEFs reencontrarem-se com o seu verdadeiro sentido, qual seja, o de constituir-se enquanto ambiente de construção de respostas calcadas no consenso, a partir da vontade das partes e vestidas de juridicidade, tendo como meio para tal a conciliação. Aqui, fala-se em uma conciliação substancial, que baseada na jurisconstrução alcança aos jurisdicionados respostas jurídico-volitivoconsensuais (Parte 2).

\section{OS JUIZADOS ESPECIAIS FEDERAIS E O MODELO DE "CONCILIAÇÃO PRAGMÁTICA"}

Os modelos decisórios em terrae brasilis acabaram por se aproximar da Análise Econômica do Direito (AED), como ficou conhecida nos pagos brasileiros a Law and Economics. Tal teoria sistematiza a aproximação entre direito e economia, fazendo com que a economia ganhe um espaço de abrangência prático-teórico em relação às demais "ciências" como um todo. O que se propõe nessa perspectiva é que a economia apresenta meios de operar o Direito desde um ponto de vista econômico de análise, operando com os materiais analítico-compreensivos ofertados pela economia. 
HOFFMAM, Fernando, MORAIS, Jose Luis Bolzan de. A prática dos Juizados Especiais Federais entre pragmatismo e respostas corretas. Revista Eletrônica Direito e Política, Programa de Pós-Graduação Stricto Sensu em Ciência Jurídica da UNIVALI, Itajaí, v.13, n.2, 20 quadrimestre de 2018. Disponível em: www.univali.br/direitoepolitica - ISSN 1980-7791

No entanto, para os limites desse trabalho, não se pretende considerar a AED como um todo, mas sim, "apenas" no que tange à obra de Richard A. Posner. Esse autor, sem dúvida alguma é um dos grandes expoentes - se não o maior - no que se relaciona com essa teoria. Oriundo da Escola de Chicago, Posner no começo da década de 1970 começa o seu percurso teórico quanto à Law and Economics, partindo da percepção de que a common law americana historicamente opera por meio de suas decisões, rumo a uma utilização eficiente de suas instituições jurídicas, políticas, econômicas, sociais, etc.

O autor norte-americano lança sua teoria a partir das bases econômicas e, partindo do principio de que sim, o mercado livre é eficiente e, assim sendo, oferece ao Direito um modelo coerente de atuar sem intervir no movimento dele próprio mercado. Desse modo, Posner eleva a eficiência à significante primeiro na perspectiva jurídico-decisória, conformando uma teoria assentada na possibilidade - para ele comprovada - de que, o magistrado ao decidir, decide de modo á eficientemente promover o "bem-estar social".

Como refere Alexandre Morais da Rosa, esse modelo prático-teórico-metodológico adere aos princípios do liberalismo econômico e, para além disso constrói uma fundamentação de que o objeto da ciência jurídica, estruturalmente, é similar ao da ciência econômica e, por esse fator, pode ser compreendido sob uma mirada economicista de análise. Com efeito, o movimento da Law and Economics busca transformar o Direito em uma verdadeira ciência racional e positiva utilizando para a análise e investigação do direito os princípios, métodos e categorias típicos do pensamento econômico. Esse processo de economicização da análise jurídica se dá de duas formas: uma positiva, que opera sobre o impacto das normas jurídicas no comportamento dos agentes econômicos, compreendidos sob o aspecto de suas decisões e bem-estar, operando por um critério tão somente econômico de maximização da riqueza; e uma normativa, que busca analisar quais as vantagens (lucro) das normas jurídicas em face do bem-estar social, analisando as consequências. ${ }^{3}$

\footnotetext{
${ }^{3}$ Quando Posner refere à análise de consequências na aplicação das normas - no processo decisório e na decisão propriamente dita - quer dizer, que assim como um agente do mercado pode se comportar racionalmente na ação econômico-mercadológica, um magistrado pode se comportar
} 
HOFFMAM, Fernando, MORAIS, Jose Luis Bolzan de. A prática dos Juizados Especiais Federais entre pragmatismo e respostas corretas. Revista Eletrônica Direito e Política, Programa de Pós-Graduação Stricto Sensu em Ciência Jurídica da UNIVALI, Itajaí, v.13, n.2, 20 quadrimestre de 2018. Disponível em: www.univali.br/direitoepolitica - ISSN 1980-7791

Porém, o teórico estadunidense no caminho de formação da sua construção teórica não utiliza o termo eficiência, mas o permuta em "maximização da riqueza", assim, o magistrado ao decidir deve buscar intransigentemente alcançar um patamar de maximização da riqueza, compreendendo essa tanto do ponto de vista econômico, quanto não econômico. A maximização da riqueza na teoria posnerniana não tem somente um caráter econômico, mas também funciona a partir de critérios sociais e políticos de maximizar a riqueza da/na sociedade.

Dessa maneira, o que se procura é mostrar que o modo de ação dos magistrados na common law - e pode-se trazer essa analise ao Brasil - não é o de procura pela eficiência da/na decisão, mas sim, que a common law está organizada de forma a evoluir histórico-decisóriamente no caminho da maximização da riqueza social. Nesse talante, o juiz não decide eficienticistamente, mas sim, atrelado a um sistema social que tem por ponto de chegada a "riqueza social" para além de uma riqueza financeira de resultados. ${ }^{4}$ No entanto, o que se nota é que Posner intenta desvincular o modelo decisório por ele defendido de uma análise meramente eficiente da decisão jurídica, o que, no ver desse autor, não consegue, pois, ao fim e ao cabo, a eficiência é o critério basilar para se alcançar uma decisão que maximize a riqueza social. A decisão maximizadora é uma decisão economicamente - e, não necessariamente socialmente - eficiente que, impulsiona a sociedade na direção da operação livre - do mercado.

No ver de Posner, constrói-se uma teoria que refuta a proximidade com o utilitarismo reconhecendo os seus limites e, pregando uma não aproximação com este. A maximização da riqueza não trabalha na perspectiva de maximizar a

racionalmente na ação jurídico-decisória de modo a sopesando os custos e benefícios, atingir uma decisão jurídica que consubstancie eficientemente os valores - econômicos - da comunidade. Assevera Posner: "Não há nada na ciência econômica que determine quais devem ser as metas de um indivíduo. Porém, quaisquer que sejam estas (algumas delas, ou mesmo todas, podem ser altruístas), presume-se que ele venha a persegui-las com as atenções voltadas para o futuro, comparando as oportunidades que se the apresentarem no momento em que for necessário fazer uma escolha" (POSNER, Richard A.. Para Além do Direito. Tradução: Evandro Ferreira e Silva. São Paulo: Martins Fontes, 2009, p. 16-17). Na obra Economia da Justiça, Posner afirma que a maximização da riqueza está vinculada ao modelo de transação do mercado, o que reveste a prática eficiente maximizadora, de uma condição de ação racional - escolha racional - compreendida no respeito às escolhas individuais, o que implica uma estreita ligação entre a AED e o neoliberalismo.

${ }^{4}$ SALAMA, Bruno Meyerhof. A História do Declínio e Queda do Eficientismo na Obra de Richard Posner. In: Revista do Instituto do Direito Brasileiro, Lisboa, n. 1, 2012, p. 435-483. 
HOFFMAM, Fernando, MORAIS, Jose Luis Bolzan de. A prática dos Juizados Especiais Federais entre pragmatismo e respostas corretas. Revista Eletrônica Direito e Política, Programa de Pós-Graduação Stricto Sensu em Ciência Jurídica da UNIVALI, Itajaí, v.13, n.2, 20 quadrimestre de 2018. Disponível em: www.univali.br/direitoepolitica - ISSN 1980-7791

felicidade ou definir possibilidades de utilidade das normas, decisões, condutas ou, seja o que for. A teoria maximizatória realiza-se na atenção á valores sociais que sistematicamente valorizam a riqueza social da comunidade, lidando com valores econômicos e não econômicos. ${ }^{5}$

Nesse sentir, Posner adverte que quando a economia adentra áreas reconhecidamente não econômicas - como o direito -, ocorre uma resistência à utilização de "valores" próprios da economia, como eficiência e maximização do valor, por tratarem-se de áreas do conhecimento humano que operam com base em padrões não-econômicos de ação/compreensão. Por tal motivo, atesta o autor que a economia teve que buscar sua normatividade inserida em uma "teoria normativa" maior, o que, durante muito tempo ligou-a ao utilitarismo. Porém, Posner, como já mencionado, aponta falhas no utilitarismo enquanto "fonte de normatividade" para a ciência econômica, e, nesse ponto, aponta um giro práticoteórico na tentativa de desvincular utilitarismo e análise econômica - do direito. Substitui utilidade por riqueza, compreendendo essa para além de uma compreensão estritamente financeira, como "a soma de todos os objetos aos quais uma sociedade atribui valor", sendo que, essa soma, deve ser ponderada em relação aos preços que cada objeto teria no mercado. O que eleva a transação de mercado à condição de paradigma de ação moralmente adequado, consistindo a operacionalidade institucional como um todo, em uma operação de - e do mercado. ${ }^{6}$

Mostra-se evidente, que a construção posnerniana opera um giro prático-teórico de caráter pragmático-eficienticista, mercadológico-economicista de apoderamento das racionalidades não econômicas por um paradigma capitalístico financeiro neoliberal, que converte a razão humana em razão de mercado. Nesse avançar, o Direito é visto como um instrumental utilitariamente concebido em favor do mercado e, os direitos, são vistos como meras externalidades em relação

5 POSNER, Richard A.. A Economia da Justiça. Tradução: Evandro Ferreira e Silva. São Paulo: Martins Fontes, 2010, p. 58-65.

6 POSNER, Richard A.. Fronteiras da Teoria do Direito. Tradução: Evandro Ferreira e Silva; Jefferson Luiz Camargo; Paulo Salles; Pedro Sette-Câmara. São Paulo: Martins Fontes, 2011, p. 98101. 
HOFFMAM, Fernando, MORAIS, Jose Luis Bolzan de. A prática dos Juizados Especiais Federais entre pragmatismo e respostas corretas. Revista Eletrônica Direito e Política, Programa de Pós-Graduação Stricto Sensu em Ciência Jurídica da UNIVALI, Itajaí, v.13, n.2, 20 quadrimestre de 2018. Disponível em: www.univali.br/direitoepolitica - ISSN 1980-7791

ao movimento livre da ação mercadológica. A racionalidade instrumental mercadológica substitui a "racionalidade humana" dos sujeitos sociais que passam a ser maximizadores da riqueza, irracionalmente despreocupados com a condição humana que os constitui. O agir racional-mercadológico de um indivíduo é o agir de modo a "escolher o melhor meio disponível para alcançar os fins por ela almejados". Tal procedimento instrumentaliza a condição humana, a condição social, como um meio para se chegar a um ideal individual de maximização da riqueza que, falsamente, maximizaria o bem-estar social?.

Embora Posner construa todo um discurso teórico para desconectar a visão de utilidade das "coisas no/do mundo" ou, das decisões jurídicas em específico, essa desconexão se dá somente - e, ainda assim, talvez se dê - em relação a padrões de utilidade vinculados ao que se pode chamar de utilitarismo clássico. Posner não consegue se desprender de "todo o utilitarismo" - para nós, de nenhum -, a maximização da riqueza opera eficienticistamente na consecução da decisão jurídica, imprimindo um visível caráter de utilidade ao modo como se decide, ao processo decisório e à decisão propriamente dita. Esse modelo processo-decisório construído pela Law and Economics implica assim, uma desoneração do magistrado em relação à história, possibilitando um processo de desautonomização do Direito, no sentido de não considerar substancialmente o(s) direito(s), mas apenas em sua operacionalidade pragmático-tecnicista destinada a apresentar uma decisão eficiente - mercadologicamente - para a sociedade. ${ }^{8}$

O critério operacional da maximização da riqueza se mostra não só utilitarista, como também, - e por causa disso -, potencialmente lesivo aos direitos humanofundamentais. Nesse sentido ao transitar por uma lógica economicista custobenefício ${ }^{9}$, não só determinados direitos - humano-fundamentais até - podem ser

7 POSNER, Richard A.. Fronteiras da Teoria do Direito. Tradução: Evandro Ferreira e Silva; Jefferson Luiz Camargo; Paulo Salles; Pedro Sette-Câmara. São Paulo: Martins Fontes, 2011, p. 320322.

8 POSNER, Richard A.. A Economia da Justiça. Tradução: Evandro Ferreira e Silva. São Paulo: Martins Fontes, 2010, p. 72-81.

9 "[...] a análise custo-benefício pode caracterizar-se como um método de avaliação pura, conduzido independentemente do uso possível de seus resultados em uma decisão; como um dos fatores a serem levados em conta em uma decisão, o que deixa a pessoa que a toma livre para rejeitar o resultado da análise com base me outras considerações; ou ainda como o próprio método de decisão. Quando usado neste último sentido, como em minha defesa do uso da análise de custo- 
HOFFMAM, Fernando, MORAIS, Jose Luis Bolzan de. A prática dos Juizados Especiais Federais entre pragmatismo e respostas corretas. Revista Eletrônica Direito e Política, Programa de Pós-Graduação Stricto Sensu em Ciência Jurídica da UNIVALI, Itajaí, v.13, n.2, 20 quadrimestre de 2018. Disponível em: www.univali.br/direitoepolitica - ISSN 1980-7791

desconsiderados, mas também, determinados sujeitos de direitos - indivíduos podem ser desconsiderados no exercício e garantia de seus direitos, desde que, a manutenção de tais direitos e o agir desses sujeitos gerem mais custo do que benefício - mascaradamente - social. Tornam-se assim, sujeitos e direitos, não mais que externalidades a serem eliminadas para a mantença do bom funcionamento do mercado. ${ }^{10}$

Nesse viés, se, na visão da AED a transação de mercado é o paradigma de ação moralmente adequado á contemporaneidade do Direito, e, mais especificamente ao sistema de justiça - ao processo -, e o neoliberalismo vê no mercado o modelo de instituição mais eficiente de gerar uma situação "ótima", assim ambos os ramos "científicos" se comunicam na conformação de um sistema de justiça produtivamente eficiente na mantença do fluxo - processo-decisório - do "mercado" jurídico. Um direito eticamente light - desubstancializado - formula um processo rápido, pois, de baixas calorias - poucos direitos e garantias -, e adornado por um sentido de propulsão do mercado - instituição neoliberal -, do mercado interno - jurídico.

Como infere Alexandre Morais da Rosa, o campo do Direito, locus privilegiado dos direitos, é colonizado por uma razão mercadológica que faz do significante eficiência, significante primeiro na cadeia significativo-interpretativocompreensiva, deslocando a lógica de proteção e garantia dos direitos em detrimento do critério mercadológico de custo-benefício. O processo é medido em números estando à procura de resultados e não de decisões democráticoconstitucionais; a sua qualidade é numérico-eficienticista e não jurídico-efetiva. Desse casamento, denota a imersão do sistema jurídico brasileiro e, sobremodo, do aparato processo-jurisdicional em um mar de certezas e seguranças do

benefício para orientar a tomada de decisões no common law, o critério de maximização da riqueza (se for esse o critério de custo-benefício utilizado) deve ser defendido. Porém, quando a análise de custo-benefício é apenas um dos elementos considerados em uma tomada de decisão e, mais claramente ainda, quando não passa de um exercício d erudição, não há necessidade de insistir em sua adequação como princípio normativo, desde que se admita que a riqueza seja um valor social, ainda que não o único" (POSNER, Richard A.. Fronteiras da Teoria do Direito. Tradução: Evandro Ferreira e Silva; Jefferson Luiz Camargo; Paulo Salles; Pedro Sette-Câmara. São Paulo: Martins Fontes, 2011, p. 133-134).

10 POSNER, Richard A.. A Economia da Justiça. Tradução: Evandro Ferreira e Silva. São Paulo: Martins Fontes, 2010, p. 90-94. 
HOFFMAM, Fernando, MORAIS, Jose Luis Bolzan de. A prática dos Juizados Especiais Federais entre pragmatismo e respostas corretas. Revista Eletrônica Direito e Política, Programa de Pós-Graduação Stricto Sensu em Ciência Jurídica da UNIVALI, Itajaí, v.13, n.2, 20 quadrimestre de 2018. Disponível em: www.univali.br/direitoepolitica - ISSN 1980-7791

mercado, que confronta eficiência e efetividade apoderando-se da segunda na sua resignificação pela primeira. ${ }^{11} \mathrm{~A}$ eficiência posnerniana disfarçada na maximização da riqueza é a mesma eficiência neoliberal imposta ao Brasil pelo Banco Mundial via Documento 319 S, que, é a mesma eficiência decantada pelo CNJ na conquista de um judiciário rápido, ágil, dócil, indefeso, e embriagado pelos signos totalitários neoliberais, capturado pela institucionalidade do mercado.

No ambiente dos JEFs essa inventividade neoliberal-mercadológica, que rapta a racionalidade jurídica e a lança numa (in)consciência cínica (des)veladora da eficiência como único critério legítimo de qualificação do sistema de justiça, opera na construção de um modelo Law and Economics de conciliação. É a construção de um ambiente conciliatório que apresenta o consenso como um coeficiente racional que possibilita a construção eficiente de um acordo, também eficiente, obedecendo á lógica custo-benefício e gerando uma continuidade produtiva do sistema. É o "modelo CNJ" de conciliação, adstrito à garantia neoliberal da ação eficiente e maximizador da riqueza social, para o mercado ${ }^{12}$.

Essa colonização dos JEFs pela racionalidade pragmático-economicista fundada na AED e, capitaneada pelo CNJ na materialização de um "esforço conjunto"13 Banco

${ }^{11}$ SALDANHA, Jânia Maria Lopes. A Jurisdição Partida Ao Meio: a (in)visível tensão entre eficiência e efetividade. In: STRECK, Lenio Luiz; MORAIS, José Luis Bolzan de (Org). Constituição, Sistemas Sociais e Hermenêutica: anuário do programa de pós-graduação em Direito da UNISINOS - N. 6. Porto Alegre: Livraria do Advogado, 2010, p. 75-100.

12 A relação entre a AED e o paradigma político-econômico neoliberal, pode ser vislumbrada a partir de duas características comuns a ambos: o respeito á escolhas individuais-racionais e a garantia da liberdade econômica. Na obra Economia da Justiça, Posner afirma que a maximização da riqueza está vinculada ao modelo de transação do mercado, o que reveste a prática eficiente maximizadora, de uma condição de ação racional - escolha racional - compreendida no respeito às escolhas individuais. Nesse passo, salienta o autor que o livre mercado, mesmo frente a quaisquer críticas igualitaristas é um modelo eficientemente maximizador da riqueza de uma sociedade (POSNER, Richard A.. A Economia da Justiça. Tradução: Evandro Ferreira e Silva. São Paulo: Martins Fontes, 2010, p. 79-81). Essa percepção de laços existentes entre a AED e o modelo neoliberal, corrobora com a assunção de um sistema de justiça neoliberal que, apontado por Antoine Garapon, sustentase sobre três vértices: eficiência - como um metavalor alicerçado por esses outros vértices -; respeito às escolhas - racionais - do jurisdicionado, concebido como um ator racional e consciente de duas decisões; segurança, que confere ao modelo processo-decisório adotado uma aparência de infalibilidade e, um poder homogeneizador das práticas processo-jurisdicionais (GARAPON, Antoine. Um Modelo de Justiça: eficiência, atores racionais, segurança. Tradução: Jânia Maria Lopes Saldanha. In: Revista Espirit, no 349, nov. 2008, p. 98-122). Esses modelos combinados resultam na prática conciliatória estatístico-eliminatória exigida pelo CNJ que embriaga os atores da justiça de proximidade, consenso e diálogo imaginada para o ambiente dos JEFs.

13 Quando se fala em "esforço conjunto" não se quer dizer que ambas as instituições ajam juntas na persecução de um sistema de justiça neoliberal(izado), mas sim, que ambas as instituições, 
HOFFMAM, Fernando, MORAIS, Jose Luis Bolzan de. A prática dos Juizados Especiais Federais entre pragmatismo e respostas corretas. Revista Eletrônica Direito e Política, Programa de Pós-Graduação Stricto Sensu em Ciência Jurídica da UNIVALI, Itajaí, v.13, n.2, 20 quadrimestre de 2018. Disponível em: www.univali.br/direitoepolitica - ISSN 1980-7791

Mundial-CNJ de adoção da eficiência como único critério legitimo para a aferição da qualidade, no que tange ao sistema de justiça, é que possibilita um modelo de conciliação calcado na domesticação do conflito, eliminação de processos e produção de acordos esvaziados de conteúdo jurídico-substancial. Gera-se uma prática conciliatória esvaziada de significado que não se materializa como fenômeno dialógico-intersubjetivo e, sim, como método impositivo-pragmático de uma decisão - e não de uma resposta - que, é a decisão da instituição.

Essa postura do CNJ é o que possibilita o surgimento da "conciliação eficiente", a "conciliação de mutirão", feita por atacado visando à eliminação processual. É a conciliação gerenciada por um magistrado também eficiente, que ativistamente comanda o processo gerenciando-o na busca pela construção de um acordo do tipo "conciliar a qualquer preço" pautado por uma escolha individual-racional, que "fundamenta" uma decisão pretensamente maximizadora da riqueza - do bemestar - social. Desse modo, os JEFs transitam de uma prática conciliatória substancial garantida pela oralidade, pela simplicidade e pelo consenso, e que também substancialmente garanta a celeridade, para uma prática conciliatória pragmática garantida pelo gerenciamento, pela eletronicização do processo e pelo ativismo do magistrado que, pragmaticamente garanta a aceleração consubstanciando um ambiente conciliatório eficiente.

Nesse rumo, é importante salientar que para determinados autores - e para os limites desse trabalho, não se fará um rol exaustivo desses trabalhos, atendo-se apenas na posição de um deles -, Posner "abandona" o critério da eficiência maximização da riqueza - na busca por uma fundamentação ético-normativa para o direito e para as ciências sociais como um todo. Para Bruno Meyerhof Salama, ${ }^{14}$ em 1990 Richard Posner teria se dado por vencido, frente aos críticos da maximização da riqueza - eficiência - como critério basilar da ordem jurídicoético-normativa. O autor norte-americano teria abandonado a eficiência a colocando-a ao lado de outros critérios tão importantes quanto ela própria. Nesse

mesmo que separadamente, adotam práticas que visam uma concepção pragmático-eficienticista de sistema de justiça que, acaba, por redundar numa prática processo-jurisdicional de viés neoliberal.

14 SALAMA, Bruno Meyerhof. A História do Declínio e Queda do Eficientismo na Obra de Richard Posner. In: Revista do Instituto do Direito Brasileiro, Lisboa, n. 1, 2012, p. 435-483. 
HOFFMAM, Fernando, MORAIS, Jose Luis Bolzan de. A prática dos Juizados Especiais Federais entre pragmatismo e respostas corretas. Revista Eletrônica Direito e Política, Programa de Pós-Graduação Stricto Sensu em Ciência Jurídica da UNIVALI, Itajaí, v.13, n.2, 20 quadrimestre de 2018. Disponível em: www.univali.br/direitoepolitica - ISSN 1980-7791

ponto, aparecem o pragmatismo e o liberalismo como "valores" que, ao lado do critério de maximização da riqueza devem pautar o modo de agira processodecisório.

A discussão entorno à eficiência deixa de ser se a eficiência pode ser igualada a justiça - o que, não pode -, e passa a como utilizar-se do conceito de eficiência para operar processo-decisóriamente de modo a beneficiar-se da análise custosbenefícios. Dessa maneira, a maximização da riqueza guiaria procedimentalmente o modo de se decidir em direito, mas não implicaria diretamente num conceito de "decisão eficiente". Apenas o procedimento seria guiado por uma visão eficienticista na trilha da análise prós e contras, custos e benefícios evidentemente, ainda, economicista-neoliberal e, assim, eficienticista. ${ }^{15}$

No entanto, ao que concerne a esse trabalho, na verdade o que se pode notar na teoria posnerniana é um refinamento da eficiência como critério ético-normativo do sistema jurídico. Posner acaba por inserir a eficiência em um complexo maior de valores relacionados à sociabilidade - originalmente, norte-americana construindo um arcabouço prático-teórico mais robusto, afim de, solidificar e, não, abandonar o critério de maximização da riqueza. A maximização da riqueza permanece sendo a base normativa do direito, bem como, o critério de aferimento do seu devido desenvolvimento enquanto sistema.

Nesse caminho, Posner adere a uma postura pragmática de análise que consubstancia o agir do magistrado em processo e o andamento do sistema de justiça e do direito enquanto fundamento ético de uma determinada sociedade. É o que se denomina de pragmatic turn, o giro pragmático posnerniano que rapta o direito para dentro de uma estrutura processo-jurisdicional técnico-pragmática, voltada para a confecção em massa de uma decisão jurídica eficiente. Cria-se uma estrutura maior, o pragmatismo, que passa a compreender a maximização da riqueza como mais um - em verdade, segue sendo o principal - critério para a

15 SALAMA, Bruno Meyerhof. A História do Declínio e Queda do Eficientismo na Obra de Richard Posner. In: Revista do Instituto do Direito Brasileiro, Lisboa, n. 1, 2012, p. 435-483. 
HOFFMAM, Fernando, MORAIS, Jose Luis Bolzan de. A prática dos Juizados Especiais Federais entre pragmatismo e respostas corretas. Revista Eletrônica Direito e Política, Programa de Pós-Graduação Stricto Sensu em Ciência Jurídica da UNIVALI, Itajaí, v.13, n.2, 20 quadrimestre de 2018. Disponível em: www.univali.br/direitoepolitica - ISSN 1980-7791

decisão jurídico-normativa, fundando a existência de um juiz pragmático ${ }^{16}$ em seu agir em processo.

Nesse sentido, é importante para Posner que os juízes assumam sinceramente as suas ponderações pragmáticas ao tomarem decisões. A prática decisória muitas vezes esconde - esconderia - por trás de um discurso retoricamente construído com bases ético-morais um fundamento pragmático instrumentalconsequencialista que insere o intérprete um uma tradição pragmaticista que desonera o presente em relação ao passado, apontando para o futuro. Em verdade, os juízes já são - seriam - pragmáticos, estando velada esta característica sob o manto de uma necessária e ilusória retórica jurídico-formalista. ${ }^{17}$

\section{A Law and Economics conforma uma sistematicidade processo-decisória orientada} pela análise custo-benefício das decisões em relação á prática econômica dominante de caráter eminentemente neoliberal e preocupada com a manutenção dos contratos e garantia da propriedade privada - dos direitos individuaisprivados. O direito em ação, via processo deve, nesse caminho, efetivar uma intransigente certeza jurídica garantidora dos laços proprietário-contratuais, de modo a potencializar a transação do mercado reduzindo os custos de transação a partir do tratamento do(s) direito(s) como externalidade(s). Tal postura do

16 Em sua obra chamada Para Além do Direito, já na introdução Richard Posner deixa claro que para ele não há um conceito único e preciso de pragmatismo. No seu entendimento o pragmatismo é uma abordagem prática e instrumental, interessada naquilo que útil e não naquilo que realmente é. É uma prática que a priori desconsidera o passado, só o levando em conta nos limites do que for útil para resolver problemas presentes e futuros. Ainda na visão do autor, a atitude pragmatista se mostra ativista, no sentido de que rejeita a ideia do que o que foi construído é - necessariamente melhor, bem como, a de que o que está por vir é por demais imprevisível para nos atermos ao futuro. "O pragmatista crê no progresso sem fingir-se capaz de defini-lo e acredita na possibilidade de alcança-lo através da ação humana calculada. Essas crenças estão ligadas ao caráter instrumental do pragmatismo, que é uma filosofia da ação e do aperfeiçoamento" (POSNER, Richard A.. Para Além do Direito. Tradução: Evandro Ferreira e Silva. São Paulo: Martins Fontes, 2009, p. 4-5). E é justamente por não tratar de qualquer pragmatismo, mas sim de um pragmatismo específico, que o citado autor constrói o conceito do que ele denomina de pragmatismo cotidiano. Ele compreende tal pragmatismo como uma atitude mental voltada para uma razão prática de agir, conformada com a prática negocial - mercadológica - que coloca a teoria em segundo plano desprezando os que ele denomina de "moralizadores e sonhadores utópicos". Esse modelo pragmático enquadra-se com as exigências de uma sociedade rápida, competitiva, objetiva, comercial, que julga as instituições, normas e decisões, pelo critério do que funciona - melhor para o mercado (POSNER, Richard A.. Direito, Pragmatismo e Democracia. Tradução: Teresa Dias Carneiro. Rio de Janeiro: Forense, 2010, p. 38-39).

17 POSNER, Richard A. Direito, Pragmatismo e Democracia. Tradução: Teresa Dias Carneiro. Rio de Janeiro: Forense, 2010, p. 42. 
HOFFMAM, Fernando, MORAIS, Jose Luis Bolzan de. A prática dos Juizados Especiais Federais entre pragmatismo e respostas corretas. Revista Eletrônica Direito e Política, Programa de Pós-Graduação Stricto Sensu em Ciência Jurídica da UNIVALI, Itajaí, v.13, n.2, 20 quadrimestre de 2018. Disponível em: www.univali.br/direitoepolitica - ISSN 1980-7791

sistema jurídico-processual e do magistrado em processo garante a ação eficiente do mercado e, por consequência a maximização da riqueza social. ${ }^{18}$

Assim, Posner edifica o espaço-tempo da adjudicação pragmática ${ }^{19}$ como mantenedor da eficiência enquanto critério de normatividade jurídica. No âmbito da adjudicação posnerniana o Estado - por meio do direito - é alijado da produção jurídico-normativa, cabendo à AED, enquanto "teoria econômica da decisão/decidibilidade" mediar os conteúdos político-jurídicos a partir da carga prático-teórica da ciência econômica. Nesse cenário, as normas gerais e abstratas do mercado governam o direito e o Estado que só são chamados à "festa" para resolver os problemas referentes às externalidades - muitas vezes humanas.

Perceba-se que, na verdade o que é tecido pelo autor norte-americano é uma desoneração aparente do uso pragmático da adjudicação, em relação á maximização da riqueza como padrão ético-normativo para o direito e, consequentemente, para as decisões jurídicas. O autor, em verdade, promove sim uma potencialização de sua teoria, inserindo a eficiência como critério central de procedimentalidade da máquina adjudicatória, o que possibilita uma expansão de sua teoria e uma agudização do processo de invasão do direito pela racionalidade econômico-neoliberal. A proposta posnerniana colocada na adjudicação

18 MORAIS DA ROSA, Alexandre; AROSO LINHARES, José Manuel. Diálogos Com a Law \& Economics. Rio de Janeiro: Lumen Juris, 2011, p. 75-76.

19 Nas linhas descritas por Posner, a adjudicação pragmática se assenta em alguns princípios assim chamados pelo próprio autor - elencados num total de doze, de maneira que não se passará nesse momento por todos eles especificamente, mas sim, de maneira geral, detendo-se mais em alguns que importam mais ao presente trabalho. Primeiramente é rechaçada a crítica feita de que a adjudicação pragmática é um modelo de tomadas de decisão ad hoc. Em verdade, no procedimento da adjudicação pragmática são levadas em consideração não só as consequências imediatas, como também as consequências sistêmicas, o que retiraria o peso de ser um sistema decisório ad hoc. Para tanto, Posner aponta que o juiz pragmático não pode nem mesmo desconsiderar a possibilidade de se utilizar pragmaticamente de uma postura formalista de análise, desde que, essa postura, seja melhor para o desenlace eficiente do caso em tela. Desse modo, a adjudicação pragmática se afasta(ria) de uma postura simplistamente consequencialista ligada ao utilitarismo, pois sopesa todas as circunstâncias atinentes à decisão tomada, sejam elas, de caráter imediato ou sistêmico. Nesse ponto, ainda cabe referir que os ditames constitucionais e a prática legislativa propõem um limite jurisdicional ao consequencialismo que não os alcança na análise. Dessa forma, o juiz é um consequencialista impuro, pois limitado, mas essa limitação é o que Ihe permite gravitar pela análise de todas as consequências, diretas ou indiretas, imediatas ou sistêmicas, casuísticas ou constitucionais etc (POSNER, Richard A.. Direito, Pragmatismo e Democracia. Tradução: Teresa Dias Carneiro. Rio de Janeiro: Forense, 2010, p. 47-55). 
HOFFMAM, Fernando, MORAIS, Jose Luis Bolzan de. A prática dos Juizados Especiais Federais entre pragmatismo e respostas corretas. Revista Eletrônica Direito e Política, Programa de Pós-Graduação Stricto Sensu em Ciência Jurídica da UNIVALI, Itajaí, v.13, n.2, 20 quadrimestre de 2018. Disponível em: www.univali.br/direitoepolitica - ISSN 1980-7791

pragmática intensifica a utilização da eficiência e realoca a maximização da riqueza no centro da construção jurídico-decisória.

Liberdade econômica, escolha racional, segurança decisória e no modo como se decide - em favor do mercado -, passam a guiar a ação processual eficiente condensadora das intenções do mercado em criar um ambiente de segurança e continuidade para as suas práticas assujeitadoras do social. O mercado precisa estar seguro de que o sistema jurídico através do sistema de justiça não irá desordenar a sua sequência lógico-pragmática de ação em busca da eficiência e utilidade prática de suas funções eminentemente capitalístico-financeiras que buscam a ordenação positiva da relação custo-benefício.

Nesse andamento, o juiz pragmaticista aparece como um maximizador da riqueza social, sobremodo quando do surgimento de um caso totalmente novo exigindo que o juiz opere como legislador. Agindo assim, o juiz pragmático estará agindo da maneira mais eficiente para a sociedade, cumprindo os ditames da eficiência como um valor social importante para a maximização da riqueza. Dessa forma, mesmo que em casos futuros as decisões não exijam a utilização de raciocínios econômicos, a "decisão será eficiente se, nos casos precedentes que a influenciaram, os juízes, desempenhando a função de legisladores, tiverem baseado sua decisão em um desejo de aumentar a eficiência".20

Instaura-se uma racionalidade autonômica em relação ao Direito e ao caso concreto que aposta na construção de respostas econômico-pragmáticas, antes mesmo de ouvir as perguntas, ou pior, ouvindo-as bem, mas the dando uma compreensão diversa da constitucional-democrática. Há um frenesi por desenvolverem-se decisões eficientes e prontas ao consumo, tanto imediato, quanto a-temporalmente na construção de ementas e súmulas que trazem em si um sentido pronto para ser acoplado aos casos, numa ode à velocidade, inserida no processo de commonlawzização do direito. As decisões, agora eficientes, surgem para responder a todas as perguntas futuras, mesmo sem saber quais

20 POSNER, Richard A. Para Além do Direito. Tradução: Evandro Ferreira e Silva. São Paulo: Martins Fontes, 2009, p. 141. 
HOFFMAM, Fernando, MORAIS, Jose Luis Bolzan de. A prática dos Juizados Especiais Federais entre pragmatismo e respostas corretas. Revista Eletrônica Direito e Política, Programa de Pós-Graduação Stricto Sensu em Ciência Jurídica da UNIVALI, Itajaí, v.13, n.2, 20 quadrimestre de 2018. Disponível em: www.univali.br/direitoepolitica - ISSN 1980-7791

serão, pois já sabem quais são as perguntas formuladas pelo mercado e as respostas que o mesmo quer. ${ }^{21}$

Essa prática decisória pertinente a esse modelo de magistrado se coaduna completamente com a prática processo-gerencial assumida pelo Judiciário brasileiro a partir das determinações do CNJ. O juiz que gerencia o processo - juiz gerente - é um magistrado que eficientemente comanda o procedimento e guia os atores processuais na obtenção da decisão pragmática que lhes cabe, ou, no caso dos JEFs, na construção do acordo não menos pragmático que irá satisfazer à institucionalidade erguida pelo mercado com base nos padrões de aferição do CNJ. O modelo processual gerencial confia ao magistrado os poderes de direção do processo/procedimento na busca por um processo justo, rápido e de baixo custo, devendo-se utilizar uma gama maior de possibilidades processo-decisórias e ambientes resolutivos de conflitos onde, ficam compreendidos os meios alternativos de resolução de conflitos.

Nasce um juiz sem limites para ir à caça dos valores eficienticistas impostos pelo mercado como ordenadores da maximização da riqueza social, inserido numa ambiência processual sem limites democrático-constitucionais à deriva na tempestade neoliberal. Os jogadores se realocam a partir do redimensionamento do campo jurídico como estrutura econômica que redefine a condição de pertencimento dos atores - jogadores - ao processo, através de laços mercadológicos de relação (des)humana. O juiz se preocupa com a eficiência da decisão, a eliminação do processo e o atingimento da meta; o jurisdicionado, com a solução rápida, mas justa, do seu caso que, passa a ser tratado como uma externalidade a ser eliminada do sistema. No entanto, eliminam-se os casos concretos, mas não os jurisdicionados, pelo menos, por enquanto.

Como salienta José Manuel Aroso Linhares, a adjudicação pragmática e o juiz pragmaticista nascem com a função de homogeneizar uma prática processodecisória heterogênea que não opera tradicionalmente através de critérios exclusivamente econômicos. Essa homogeneização se dá pelo emprego da

${ }^{21}$ STRECK, Lenio Luiz. O Que É Isto - decido conforme minha consciência? Porto Alegre: Livraria do Advogado, 2010, p. 64. 
HOFFMAM, Fernando, MORAIS, Jose Luis Bolzan de. A prática dos Juizados Especiais Federais entre pragmatismo e respostas corretas. Revista Eletrônica Direito e Política, Programa de Pós-Graduação Stricto Sensu em Ciência Jurídica da UNIVALI, Itajaí, v.13, n.2, 20 quadrimestre de 2018. Disponível em: www.univali.br/direitoepolitica - ISSN 1980-7791

maximização da riqueza ancorada numa análise de custos e benefícios da decisão ao mercado. Procura-se tratar os ambientes processo-jurisdicionais, com uma procedimentalidade padrão insculpida no modus operandi pragmáticomercadológico da AED. ${ }^{22}$ A Law and Economics lança seus tentáculos sobre o direito e, sobretudo, sobre a esfera processo-jurisdicional, vertida em espaço mercadológico habitado pelo neoliberalismo. No Brasil, seja pela ação do CNJ após sua criação, seja pela ação governamental anterior invertendo o paradigma administrativo de burocrático á gerencial, o sistema de justiça se neoliberalizou no caminho de uma espacialidade fragmentada e esvaziada no que tange á conteúdos substanciais de construção das decisões.

Nesse jaez, o que ocorre é que relativamente à ambiência dos JEFs, para além da adjudicação pragmática funda-se uma espécie da "conciliação pragmática" que rompe completamente com os fundamentos originários da prática conciliatória e, da própria nova institucionalidade construída com a intenção de oferecer aos sujeitos sociais um espaço-tempo processual alternativo e, efetivamente célere. A lógica democrático-constitucional dos JEFs é invertida pelo sistema em uma lógica neoliberal-economicista que desnatura o sistema pensado e o joga na insensatez da eficiência produtiva que mantem o fluxo do mercado jurídico das decisões.

A conciliação sob as vistas da AED é mirada pragmaticamente como método eliminatório de processos, normalizador de conflitos e gerador de números estatísticos, em meio á um processualismo numerológico que cumpre as metas impostas pelo $\mathrm{CNJ}$, na trilha do paradigma mercadológico imposto pelo neoliberalismo. Perde-se assim, o real sentido da criação dos JEFs que, vê deveria ver, ou, inicialmente via - a conciliação de maneira substancial, encadeada na oralidade, na simplicidade e no consenso, como condição de possibilidade para um judiciário mais democrático. A conciliação é fenômeno construtor de respostas substancialmente consensuais e, não, método fazedor de decisões pragmaticamente autônomas e vazias de conteúdo.

22 MORAIS DA ROSA, Alexandre; AROSO LINHARES, José Manuel. Diálogos Com a Law \& Economics. Rio de Janeiro: Lumen Juris, 2011, p. 170. 
HOFFMAM, Fernando, MORAIS, Jose Luis Bolzan de. A prática dos Juizados Especiais Federais entre pragmatismo e respostas corretas. Revista Eletrônica Direito e Política, Programa de Pós-Graduação Stricto Sensu em Ciência Jurídica da UNIVALI, Itajaí, v.13, n.2, 20 quadrimestre de 2018. Disponível em: www.univali.br/direitoepolitica - ISSN 1980-7791

Nesse caminhar o espaço-tempo processo-jurisdicional compreendido pelos JEFs deve ser realinhado á proposta originária para a qual foi pensado e instituído. Os JEFs devem ser recompreendidos a partir da recompreensão da conciliação inserida no paradigma do desejo pelo consenso num caminho de construção intersubjetivo-dialogal de respostas conformadas na possibilidade franca de fala dos atores processuais - juiz e partes - inseridos numa perspectiva jurisconstrutiva de consenso decisório. Essa nova atividade conciliatória orientada pelo consenso, propicia a construção de um ambiente substancial de construção de respostas consensualmente nascidas e, não pragmaticamente inventadas.

\section{OS JUIZADOS ESPECIAIS FEDERAIS COMO LOCUS DE RESPOSTAS CONSENSUALMENTE JURISCONSTRUÍDAS}

Nesse percurso, a que se entender o surgimento dos JEFs abrangidos por um novo modelo de processo - civil - que se origina na fecundidade constitucionaldemocrática materializada a partir da promulgação da Constituição Federal de 1988. Há na criação dos JEFs um nítido intento de proporcionar aos cidadãos como já foi dito - uma esfera processo-jurisdicional diversa das apresentadas pelo paradigma moderno-racionalista e mantidas até os dias de hoje.

Esse novo processualismo torna-se responsável por pensar o direito de maneira autônoma, como condição de possibilidade para garantir e efetivar os conteúdos sociais. Essa autonomia terá na ambiência dos JEFs um lugar privilegiado de fala, na fala dos atores do conflito. Esse é - um dos meios - o meio apto a levar ao direito as complexidades sociais do nosso tempo. Ou seja, o processo de um Estado Democrático de Direito acontece efetivamente quando os direitos e garantias fundamentais acontecem no desvelamento de seu ser - ser de um ente -, perfectibilizados na decisão jurídica que, nos JEFs, materializa-se em uma resposta consensual jurisconstruída. ${ }^{23}$

Dessa maneira, quebra-se a prática conciliatória pragmática que caracteriza o acontecer processo-jurisdicional dos JEFs na atualidade, subscrevendo os JEFs em

23 BOLZAN DE MORAIS, Jose Luis. SPENGLER, Fabiana Marion. Mediação e Arbitragem: alternativas à jurisdição!. Porto Alegre: Livraria do Advogado, 2008. Passim. 
HOFFMAM, Fernando, MORAIS, Jose Luis Bolzan de. A prática dos Juizados Especiais Federais entre pragmatismo e respostas corretas. Revista Eletrônica Direito e Política, Programa de Pós-Graduação Stricto Sensu em Ciência Jurídica da UNIVALI, Itajaí, v.13, n.2, 20 quadrimestre de 2018. Disponível em: www.univali.br/direitoepolitica - ISSN 1980-7791

uma praticidade procedimental conformada na busca pelo consenso. O campo dos Juizados deve ser notado como campo de atuação das partes e do magistrado na consecução da resposta "jurisdicional" compartilhada em ambas as vontades - a vontade autônoma das partes e a vontade racional do direito que, também deve ser autônoma, por exemplo, face à política ou à economia.

Nessa nova prática processual alicerçada nos JEFs, não é possível partir de uma análise meramente pragmática do caso concreto, o que resultaria tão só uma decisão - em forma de acordo - que esvaziaria a procedimentalidade aqui pensada enquanto lugar do consenso. Uma decisão pragmática não levaria em conta o conflito - o caso concreto - nem as vontades autônomas das partes sobre o mesmo - conflito -, mas constituiria uma decisão que fosse a considerada melhor para aquela situação, com base em razões estratégicas a orientar uma lógica decisória consequencialista que, em nada, se aproximaria do que foi concebido para esse novo espaço institucional. ${ }^{24}$

O juiz pragmatista, ao operar na institucionalidade dos JEFs, agiria de acordo com o que fosse melhor - no sentido de maximização da riqueza social - para o futuro da comunidade, sem levar em conta o passado comunitário-institucional, bem como sem ater-se - ou quiçá dar espaço - ao diálogo produzido pelas partes em processo. A pragmática decisória conforma tão só uma decisão que deve ser eficiente em relação ao futuro da comunidade, não há espaço para o consenso, pois, este, não é previsível, nem mesmo, garantia de eficiência para a comunidade - para o mercado.

No horizonte pragmático de construção das repostas jurídico-sociais devidas à comunidade, opera-se com base em uma "abordagem prática" que trata a decisão jurídica - e isso já vilipendiaria qualquer teoria da decisão democráticoconstitucionalmente pensada - como um acontecimento político e, assim sendo, o magistrado/conciliador e, todos que operam com a decisão - no caso dos JEFs, também as partes - devem agir de modo a contemplar o "problema prático

24 DWORKIN, Ronald. O Império do Direito. Tradução: Jefferson Luiz Camargo. São Paulo: Martins Fontes, 2007, p. 180-181. 
HOFFMAM, Fernando, MORAIS, Jose Luis Bolzan de. A prática dos Juizados Especiais Federais entre pragmatismo e respostas corretas. Revista Eletrônica Direito e Política, Programa de Pós-Graduação Stricto Sensu em Ciência Jurídica da UNIVALI, Itajaí, v.13, n.2, 20 quadrimestre de 2018. Disponível em: www.univali.br/direitoepolitica - ISSN 1980-7791

imediato" que qualquer decisão jurídica trata. ${ }^{25}$ É visível que tal concepção se aplicada ao espaço-tempo construtivo-decisório dos JEFs desvirtua por completo o que foi pensado para esse novo espaço, pois as vontades das partes não têm possibilidade de vir-à-fala na constituição de um acordo tão só, politicamente eficiente de vontades.

Essa prática processo-decisória pragmático-eficienticista desnatura por completo o lugar de fala do qual deve surgir qualquer decisão - resposta consensual oriunda dos JEFs. Esse lugar de fala remete a uma tradição oral, informal, dialogada e ordenada pela busca do consenso, nas falas efetivamente autônomas das partes em processo e em conflito, o que faz a resposta formulada compartilhadamente transitar para fora de qualquer elemento apenas ocasional de conformação da decisão - que é formulada pelas partes e não somente pelo magistrado, mesmo que, em princípio, se trate de uma "decisão jurídica".

Na perspectiva da AED, como salienta Ronald Dworkin, a questão gira unicamente em torno do aumento ou não da riqueza - social - da sociedade, desonerando-se de uma compreensão mais ampla no sentido ético-moral, no sentido de, se a maximização da riqueza proporcionou um aumento do "valor social" - ético-moral - da comunidade. Dito de outro modo, a maximização da riqueza social propiciou efetivamente uma sociedade melhor, em melhores condições de mundo, ou, meramente utilizou-se de um critério eficienticista instrumental para tomar determinadas decisões violadoras de direitos ${ }^{26}$.

As posturas pragmatistas ceticamente miram o direito desconfiando do mesmo e, com isso, de pretensões juridicamente tuteladas que genuinamente conformem um "modo de agir" do sistema na proteção destas - pretensões. Não há um lugar de fala constituído a partir da Constituição, de um regime político democrático, de uma prática jurídico-institucional assentada; há apenas, uma função de melhora das condições comunitárias com vistas para o futuro, desconsiderando que os

25 DWORKIN, Ronald. A Justiça de Toga. Tradução: Jefferson Luiz Camargo. São Paulo: Martins Fontes, 2010, p.72-73.

26 DWORKIN, Ronald. Uma Questão de Princípio. Tradução: Luís Carlos Borges. Tradução: Luís Carlos Borges. São Paulo: Martins Fontes, 2005, p. 358-359. 
HOFFMAM, Fernando, MORAIS, Jose Luis Bolzan de. A prática dos Juizados Especiais Federais entre pragmatismo e respostas corretas. Revista Eletrônica Direito e Política, Programa de Pós-Graduação Stricto Sensu em Ciência Jurídica da UNIVALI, Itajaí, v.13, n.2, 20 quadrimestre de 2018. Disponível em: www.univali.br/direitoepolitica - ISSN 1980-7791

sujeitos sociais - os cidadãos pertencentes à comunidade - tem garantidos a si, direitos que se sobrepõe a qualquer possibilidade mesmo que clara de melhora futura da comunidade. ${ }^{27}$

Essa situação revela a composição de um processo que ligado a estruturas modernas, coloca-se hipermoderno ao potencializar as características avençadas ao processo pela modernidade, a partir da modelagem neoliberal que radicaliza os poderes e desejos do capitalismo industrial, vertendo-o em capitalismo financeiro. O que se pode chamar de hipermodernidade processual confronta o modelo substancial de processo preconizado pela constitucionalidade, com um modelo processual pragmático que obedece somente ao princípio supremo da anomia jurídico-social. ${ }^{28}$ Nos JEFs, essa manifestação hipermoderna da jurisdição ocorre na lógica de monetarização do conflito e sua consequente normalização em um acordo vazio como o princípio do mercado, bem como, e sobremodo, na atmosfera produtivo-aceleratória que passa a abranger a procedimentalidade dos JEFs. A velocidade alçada á condição de critério de medida para a eficiência, desloca a celeridade em direção á aceleração da prestação jurisdicional num movimento único de produção de acordos e eliminação de processos.

Nesse rumo, fica evidente que a experiência dos Juizados Especiais Federais, deve ser reconstituída, em meio a outra ordem paradigmático-processual. Os JEFs devem habitar o que se pode chamar de um processualismo antimoderno, que os apresente como um ambiente democrático-processual, capaz de apresentar à sociedade respostas substancialmente constitucionais construídas a partir do consenso. Por assim dizer, o ambiente jurídico-decisório imaginado para os JEFs precisa desejar - aderindo à - a Constituição - como comunidade de princípios enquanto instituidora de um novo modus interpretativo-compreensivo, que caminha pelos caminhos por ela - Constituição - trilhados e, que oferece aos

27 DWORKIN, Ronald. O Império do Direito. Tradução: Jefferson Luiz Camargo. São Paulo: Martins Fontes, 2007, p. 194-196.

28 SALDANHA, Jânia Maria Lopes. A "Paradoxal" Face Hipermoderna do Processo Constitucional: um olhar sobre o direito processual brasileiro. In: Revista Estudios Constitucionales, Talca, ano $8, n^{\circ} 2,2010$, p. $675-706$. 
HOFFMAM, Fernando, MORAIS, Jose Luis Bolzan de. A prática dos Juizados Especiais Federais entre pragmatismo e respostas corretas. Revista Eletrônica Direito e Política, Programa de Pós-Graduação Stricto Sensu em Ciência Jurídica da UNIVALI, Itajaí, v.13, n.2, 20 quadrimestre de 2018. Disponível em: www.univali.br/direitoepolitica - ISSN 1980-7791

sujeitos jurídico-sociais um espaço de concretização e desvelamento do direito no caso concreto.

O espaço-tempo processo-decisório nesse momento deve guardar relação direta com o caso concreto e com o seu devido desvelar. Rompe-se com o mundo instituído pela modernidade jurídica castradora do novo, bem como, com o mundo desinstituído hipermoderno e, percebe-se no processo - democráticoconstitucionalizado -, ambientado nos JEFs, a possibilidade do novo a partir da facticidade, da existencialidade do fato da vida levado à prática construtivodecisória e, assim, levando a resposta jurisconstruida 29.

A conformação da resposta jurisconstruida inerente aos JEFs, não pode se dar de maneira circunstancial como pretende a racionalidade neoliberal, a partir da utilização da AED como "teoria processo-decisória" mais afeita ao Direito e, nesse rumo, aos Juizados. O Direito, como afirma Ronald Dworkin, não pode ser tratado como mera questão de política, mas sim, é para, além disso, questão de princípio. Por tal, a resposta construída consensualmente pelas partes processo-conflitivas, surge envolta em um todo principiológico comunitário forjado em "ideais" de integridade e coerência. Há como condição primeira - mas não plenipotenciária instituidora dessa resposta uma comum-unidade principiológica.

Desse modo, seguindo a trilha do jusfilósofo norte-americano, a resposta consensualmente jurisconstruída nasce conformada por referenciais de integridade e coerência do/no direito. A resposta - decisão jurídica - nasce em meio ao que Dworkin denomina de comunidade de princípios, o que onera o magistrado a participar da jurisconstrução tendo em seu horizonte um todo principiológico que o conforma em ação. Um juiz-intérprete que opera por padrões de integridade e coerência em meio à comunidade de princípios aceita a condição de que o ideal de integridade no Direito estabelece direitos que possibilitam aos litigantes exigir uma decisão dele. O caso concreto - o caso em tela - deverá ser julgado de acordo com a melhor concepção sobre o que as normas jurídicas da comunidade exigiam

29 BOLZAN DE MORAIS, Jose Luis; SPENGLER, Fabiana Marion. Mediação e Arbitragem: alternativas à jurisdição!. Porto Alegre: Livraria do Advogado, 2008, p. 121. 
HOFFMAM, Fernando, MORAIS, Jose Luis Bolzan de. A prática dos Juizados Especiais Federais entre pragmatismo e respostas corretas. Revista Eletrônica Direito e Política, Programa de Pós-Graduação Stricto Sensu em Ciência Jurídica da UNIVALI, Itajaí, v.13, n.2, 20 quadrimestre de 2018. Disponível em: www.univali.br/direitoepolitica - ISSN 1980-7791

ou permitiam à época, bem como a integridade comum-unitária exige que essas normas sejam aplicadas com coerência. ${ }^{30}$

Nesse meio nasce uma resposta jurídico-consensual conformada político, jurídico e socialmente, que não deixa espaços livres para escolhas arbitrarias, seja do intérprete, seja do mercado. A resposta jurídico-volitiva vem blindada por uma textura viva principiológica que adjudica para si a legitimidade dela mesma decisão, juntamente com a legitimidade efetiva emanada da vontade autônoma das partes em acordo. Constrói-se um espaço-tempo hermenêutico-integrativoconsensual, por excelência, democrático-constitucionalizado, que lança os olhos sobre o passado, considerando o presente e, visando o futuro.

A resposta jurisconstruída que exsurge desse corpo vivo principiológico de integridade e coerência nasce no caso concreto, que é irrepetível. Assim, fica claro que o caso concreto conforma a decisão jurídica - na e com a resposta jurisconstruída - para que através dele - caso concreto - reflita-se no seio da comunidade jurídico-político-social de forma integra e coerente os padrões exarados pela comum-unidade de princípios. Surge a resposta correta ao caso concreto, fecundada no ambiente comunitário político-jurídico-social, que, não será a única, nem a melhor resposta, mas "apenas" a resposta correta para aquele caso concreto - construída a partir daquela situação de diálogo - que, embora também, não devam ser vistos como únicos, não podem ser vistos como apenas mais um em uma multidão casuístico-consensual. ${ }^{31}$

Seguindo caminho, ergue-se um projeto de jurisdição que se mostra histórico na linha do que acredita Ronald Dworkin. Na prática processo-decisória dos JEFs, é necessário um ponto de equilíbrio entre a vontade das partes, a atuação do magistrado e, entre o que a tradição sobre a qual está assentada o nosso país, sobremodo, a partir de 1988 tem a dizer a ambos enquanto envoltos na relação de consenso. Isso não quer dizer que a partir da vontade autônoma das partes,

30 DWORKIN, Ronald. O Império do Direito. Tradução: Jefferson Luiz Camargo. São Paulo: Martins Fontes, 2007, p. 262-263.

31 STRECK, Lenio Luiz. Verdade e Consenso: Constituição, hermenêutica e teorias discursivas. Rio de Janeiro: Lumen Juris, 2011, p. 363-366. 
HOFFMAM, Fernando, MORAIS, Jose Luis Bolzan de. A prática dos Juizados Especiais Federais entre pragmatismo e respostas corretas. Revista Eletrônica Direito e Política, Programa de Pós-Graduação Stricto Sensu em Ciência Jurídica da UNIVALI, Itajaí, v.13, n.2, 20 quadrimestre de 2018. Disponível em: www.univali.br/direitoepolitica - ISSN 1980-7791

conciliada - mediada - pelo magistrado, não se possa chegar a um acordo que não esteja claramente exposto no arcabouço democrático-constitucional, desde que não o fira de morte. Essa relação com a história e com "o que foi dito", implica sim, a impossibilidade de se fazer acordos circunstanciais que não respeitam a vontade das partes ou, à desautonomiza em nome da maximização da riqueza da eficiência neoliberal. ${ }^{32}$

A resposta correta no horizonte dos JEFs, não pode ser vista apenas no sentido de ser um acordo - autentico ou não - entre as partes. Há um "acordo" anterior entre o acordo das partes oriundo do consenso e a tradição constitucional brasileira pós1988 que, dá suporte às decisões jurídicas e - deve dar também - às respostas jurídico-volitivo-consensuais. As respostas jurisconstruídas não são corretas apenas porque nascem do diálogo entre as partes, gerador do consenso. São corretas, sobremodo, porque pertencem a um arcabouço jurídico-político-social pré-compreendido na resposta - jurisconstruída. Para ficar claro, a respostas jurisconstruídas pelo consenso a partir do fenômeno da conciliação acontecem no horizonte hermenêutico "aberto" pela Constituição. ${ }^{33}$

Nesse passo, os acordos oriundos do diálogo entre os atores processo-conflitivos devem estar adstritos às vontades autônomas das partes em processo, não podendo partir o acordo de uma vontade induzida pelo magistrado/conciliador em nome de uma pretensa ação eficiente por parte do Estado. Ao se conciliar a partir de direitos sociais - fundamentais - deve estar claro que partiu da vontade autônoma do cidadão-segurado-jurisdicionado o desejo de abrir mão de parte de seu crédito previdenciário, por ser o melhor para ele naquela situação. O que, não pode haver, de maneira alguma, é a imposição ao cidadão em juízo, como condição de possibilidade para receber seu crédito em tempo hábil, ter que abrir mão de parte substancial do crédito como parte do acordo.

32 DWORKIN, Ronald. A Justiça de Toga. Tradução: Jefferson Luiz Camargo. São Paulo: Martins Fontes, 2010, p. 172-176.

33 STRECK, Lenio Luiz. Verdade e Consenso: Constituição, hermenêutica e teorias discursivas. Rio de Janeiro: Lumen Juris, 2011, p. 347-351. 
HOFFMAM, Fernando, MORAIS, Jose Luis Bolzan de. A prática dos Juizados Especiais Federais entre pragmatismo e respostas corretas. Revista Eletrônica Direito e Política, Programa de Pós-Graduação Stricto Sensu em Ciência Jurídica da UNIVALI, Itajaí, v.13, n.2, 20 quadrimestre de 2018. Disponível em: www.univali.br/direitoepolitica - ISSN 1980-7791

Desse modo, não se discute a possibilidade de acordar-se sobre direitos sociais fundamentais - mas sim, o modo como esse acordo é - deve - ser feito. O acordo deve ser procurado no consenso dialogado entre os atores processo-conflitivos acontecendo, na resposta jurídico-volitivo-consensual jurisconstruida no ambiente democrático de fala permitido pelos JEFs. Nesse momento, há - haverá - uma blindagem substancialmente constitucional à resposta construída, pois, esta, originou-se na vontade das partes em diálogo com a "vontade" constitucional.

Nessa maré, o que se exige é um modelo processual democrático-constitucional que abarque os JEFs e os configure também como uma processualidade constitucional-democrática que, refaça o caminho da eficiência á efetividade. A eficiência é economicista, pragmática e sistêmica; a efetividade é jurídica, substancial e comunitária. No retrilhar do caminho, partindo-se rumo à efetividade como possibilitadora da celeridade encadeada á substancialidade constitucional, se estruturam os JEFs na perspectiva da construção de respostas consensuais compartilhadas, para os quais originalmente - pelo menos em parte - eles foram pensados e estruturados.

\section{CONSIDERAÇÕES FINAIS}

Fica claro, que a visão pragmático-eficienticista que toma forma no contexto da neoliberalização do(s) sistema(s) de justiça, conforma um Judiciário orientado pela eficiência, pela produção de decisões e pela eliminação de processos, gerando números e, ao mesmo tempo, descaracterizando direitos. Nesse momento, surge a "conciliação pragmática" como modelo de solução de conflitos mais afeito à jurisdicionalidade dos JEFs, totalmente de acordo com as práticas propostas pelo $\mathrm{CNJ}$ e pelo Banco Mundial, conformando um paradigma eficienticista de direito e de jurisdição (Parte 1).

Desse modo, é claramente necessário que se repense os JEFs sob o prisma da constitucionalidade, da democratização do(s) sistema(s) de justiça e do acesso afetivo á justiça. Nesse caminho, os JEFs precisam de um novo olhar para a conciliação, que á constitua como o espaço-tempo de ação do jurisdicionado na construção de respostas jurídico-volitivo-consensuais, que efetivamente resolvam e "tratem" o conflito (Parte 2). 
HOFFMAM, Fernando, MORAIS, Jose Luis Bolzan de. A prática dos Juizados Especiais Federais entre pragmatismo e respostas corretas. Revista Eletrônica Direito e Política, Programa de Pós-Graduação Stricto Sensu em Ciência Jurídica da UNIVALI, Itajaí, v.13, n.2, $2^{\circ}$ quadrimestre de 2018. Disponível em: www.univali.br/direitoepolitica - ISSN 1980-7791

\section{REFERÊNCIAS DAS FONTES CITADAS}

BOLZAN DE MORAIS, Jose Luis; SPENGLER, Fabiana Marion. Mediação e Arbitragem: alternativas à jurisdição!. Porto Alegre: Livraria do Advogado, 2008.

DWORKIN, Ronald. A Justiça de Toga. Tradução: Jefferson Luiz Camargo. São Paulo: Martins Fontes, 2010.

DWORKIN, Ronald. O Império do Direito. Tradução: Jefferson Luiz Camargo. São Paulo: Martins Fontes, 2007.

DWORKIN, Ronald. Uma Questão de Princípios. Tradução: Luís Carlos Borges. Tradução: Luís Carlos Borges. São Paulo: Martins Fontes, 2005.

MORAIS DA ROSA, Alexandre; AROSO LINHARES, José Manuel. Diálogos Com a Law \& Economics. Rio de Janeiro: Lumen Juris, 2011.

POSNER, Richard A.. A Economia da Justiça. Tradução: Evandro Ferreira e Silva. São Paulo: Martins Fontes, 2010.

POSNER, Richard A.. Direito, Pragmatismo e Democracia. Tradução: Teresa Dias Carneiro. Rio de Janeiro: Forense, 2010.

POSNER, Richard A.. Fronteiras da Teoria do Direito. Tradução: Evandro Ferreira e Silva; Jefferson Luiz Camargo; Paulo Salles; Pedro Sette-Câmara. São Paulo: Martins Fontes, 2011.

POSNER, Richard A.. Para Além do Direito. Tradução: Evandro Ferreira e Silva. São Paulo: Martins Fontes, 2009.

SALAMA, Bruno Meyerhof. A História do Declínio e Queda do Eficientismo na Obra de Richard Posner. In: Revista do Instituto do Direito Brasileiro, Lisboa, n. 1, 2012, p. 435-483.

SALDANHA, Jânia Maria Lopes Saldanha. A Jurisdição Partida Ao Meio: a (in)visível tensão entre eficiência e efetividade. In: STRECK, Lenio Luiz; MORAIS, José Luis Bolzan de (Org). Constituição, Sistemas Sociais e Hermenêutica: anuário do programa de pós-graduação em Direito da UNISINOS - N. 6. Porto Alegre: Livraria do Advogado, 2010.

SALDANHA, Jânia Maria Lopes. A "Paradoxal" Face Hipermoderna do Processo Constitucional: um olhar sobre o direito processual brasileiro. In: Revista Estudios Constitucionales, Talca, ano 8, n 2, 2010, p. 675-706.

STRECK, Lenio Luiz. O Que É Isto - decido conforme minha consciência?. Porto Alegre: Livraria do Advogado, 2010.

STRECK, Lenio Luiz. Verdade e Consenso: constituição, hermenêutica e teorias discursivas. Rio de Janeiro: Lumen Juris, 2011.

Recebido em: 30/10/2017

Aprovado em: 10/06/2018 